


\section{Contact System Activation in Severe Infectious Diseases}

\section{Sonja Oehmcke ${ }^{\#}$ and Heiko Herwald}

From the Department of Clinical Sciences, Division of Infection Medicine, Lund University, SE-22184 Lund, Sweden.

"To whom correspondence should be addressed: Department of Clinical Sciences, Division of Infection Medicine, BMC, B14, Lund University, Tornavägen 10, SE-221 84 Lund, Sweden, Phone +46-46-2228592, Fax +46-46-157756, e-mail sonja.oehmcke@med.lu.se 


\footnotetext{
1 Abstract

2 Hemostasis is a sensitive and tightly regulated process, involving vascular

3 endothelium and blood cells as well as factors of the coagulation and fibrinolytic

4 cascades. In severe and invasive infectious diseases the equilibrium between the

5 procoagulant and anticoagulant status of the host may change dramatically and can

6 induce life-threatening complications. A growing body of evidence suggests that the

7 contact system, also known as the intrinsic pathway of coagulation or kallikrein/kinin

8 system, participate in these processes. Contact activation leads to the release of the

9 highly potent proinflammatory peptide bradykinin and initiates the intrinsic pathway of

10 coagulation. Several studies have shown a systemic activation of the contact system

11 in animal models of severe bacterial infections and similar findings were also

12 reported when monitoring patients suffering from sepsis, severe sepsis, or septic

13 shock. Complications resulting from a systemic activation of the contact system are

14 pathologically high levels of bradykinin, consumption of contact factors, and a

15 subsequent induction of inflammatory reactions. These conditions may contribute to

16 serious complications such as hypotension and vascular leakage. Here we

17 summarize the state of the art in this field of research with a focus on the contact

18 system and we also discuss a potential role for the contact system as a target for the

19 development of novel antimicrobial strategies. 
2 Sepsis, severe sepsis, and septic shock are complications derived from bacterial

3 infections that are the second leading cause of death among patients in non-coronary

4 intensive care units and the $10^{\text {th }}$ leading cause of death in the United States [1].

5 Despite treatment with antibiotics and an improved intensive care system, the

6 incidence of sepsis and the number of sepsis-related deaths are increasing and they

7 are associated with mortality rates between 30 and $70 \%$ [2]. The molecular

8 mechanisms behind the pathogenesis of these life-threatening conditions are still not

9 fully understood. A growing body of evidence, however, suggests that the interaction

10 between bacterial pathogens and the host defense machinery results in an

11 uncontrolled and overwhelming inflammatory response. This includes a systemic

12 activation of proteolytic host cascades such as the complement and coagulation

13 cascades as well as the contact system, also known as the kallikrein/kinin system or

14 intrinsic pathway of coagulation [3].

\section{The contact system}

Once activated the contact system is involved in the regulation of hemostatic and inflammatory processes [4, 5]. The system contains 4 components: three serine proteinases: factor XI (FXI), factor XII (FXII), plasma kallikrein, and the nonenzymatic co-factor, high molecular weight kininogen (HK), respectively. The latter protein consists of six domains, of which domain $1-3$ are cystatin-like. The bradykinin sequence is found in domain 4 , and domain 5 carries a zinc-binding site and a binding site for negatively charged surfaces [4-7]. As early as 1995 it was shown that $\mathrm{HKH} 20$, a peptide derived from HK domain 5 (amino acids 479 to 498), spanning the binding site for negatively charges surfaces, is able to interact with $M$ protein, an important streptococcal virulence factor [6]. Thereafter, it was also reported that $\mathrm{HKH} 20$ mimics the HK binding site to many eukaryotic cell types [8-10], binds to lipopolysaccharide [11], and has antimicrobial activity [12]. In addition another HK-derived peptide (amino acids 420 to 513) covering the HKH2O sequence was found to down-regulate endothelial cell proliferation and migration and inhibit angiogenesis [13]. Finally, domain 6 mediates the binding to plasma kallikrein and

32 FXI [14].

33 The four contact factors normally circulate in the bloodstream or are bound to the 34 surface of different cell types, including endothelial cells, platelets and 35 polymorphonuclear neutrophils (PMNs). Negatively charged surfaces such as kaolin 36 and dextran-sulfate as well as nucleotides (DNA and RNA) have been reported to 37 assemble and activate the contact system [10, 15-17]. While the molecular 
1 mechanisms leading to a contact activation on kaolin and dextran-sulfate are more or

2 less understood, there are controversial reports addressing the mode of activation on

3 cellular surfaces. Therefore, the latter will not be discussed in this article. FXII bound

4 to kaolin is converted into an active proteinase ( $\mathrm{FXIla)}$ by autoactivation. This is

5 followed by a FXIla-mediated activation of plasma kallikrein, a process referred to as

6 limited proteolysis. Plasma kallikrein in turn is able to increase of the activity of FXIla,

7 which then enables FXIla to activate FXI and subsequently the intrinsic pathway of

8 coagulation (Fig.1) eventually leading to the formation of a fibrin network.

9 Inflammatory reactions are evoked by the processing of HK via plasma kallikrein,

10 resulting in the release of bradykinin (BK) from its precursor. BK is a potent 11 multifunctional pro-inflammatory peptide consisting of nine amino acids. Many effects

12 of $\mathrm{BK}$ are induced by its ability to trigger the induction of second-generation

13 mediators such as nitric oxide, prostaglandins and leukotrienes. In addition BK is 14 involved in many other processes such as the regulation of blood pressure, induction 15 of fever, increase of vascular permeability and capillary leakage, edema formation, 16 and hypotension [4, 5]. Notably, the half-life of BK in the circulation is extremely short 17 (< 10 seconds) and thus, increased levels of BK in patients with various underlying 18 diseases are difficult to monitor. There are, however, two conditions that are 19 associated with high levels of BK namely hereditary angioedema (caused by a 20 deficiency of $\mathrm{C} 1$-inhibitor, an inhibitor of the contact and the complement system) and 21 severe infectious diseases (for reviews see $[18,19]$ ).

\section{Sepsis and Coagulation}

24 Sepsis is defined as a systemic inflammatory response syndrome (SIRS) with an 25 underlying infection. Complications from these life-threatening conditions are often 26 expanded when the initial appropriate host response to the invading pathogen is 27 amplified and becomes deleterious. Clinical symptoms of the onset are frequently 28 conflictive (fever or hypothermia, tachycardia, leukocytosis or leucopenia), and if 29 untreated, patients may develop respiratory or renal failure, coagulopathy and non30 responsive hypotension. The immunological reactions under these conditions are 31 complex and can alter over time. The early proinflammatory response is 32 characterized by an overwhelming stimulus and triggers PMNs and macrophages to 33 an excessive production of cytokines, chemokines, and other proinflammatory 34 mediators. Other complications, such as secondary ischemia (shock) and hypoxia 35 (lung injury) can also amplify the proinflammatory response [20]. This boost of 36 inflammatory reactions may lead to a shift from a normally beneficial inflammatory 37 response to hyper-inflammatory and counterproductive reactions, which eventually 
1 cause more damage than the host can tolerate. It is now believed that the initial

2 hyper-inflammatory phase accounts for some early deaths, although most patients

3 die at later stages due to their prolonged immunosuppressive state [21].

4 Studies of host-parasite interactions taking place in the circulation have significantly contributed to our understanding of the molecular mechanisms that lead to the induction of systemic inflammatory reaction. Host effectors systems that are of interest here are the contact-, complement-, fibrinolytic-, and coagulation systems. The latter is activated by the induction of tissue factor (TF) expression on mononuclear and endothelial cells, which is often triggered by bacteria or bacterial products [22]. An up-regulation of TF on the surface of these cells can lead to a systemic activation of the coagulation system that may progress to additional complications such as disseminated intravascular coagulation (DIC). DIC is characterized by the formation of microthrombi in microvasculature [23]. At the initial stage clot formation occurs intra - and extravascularly due to thrombin activation (hypercoagulopathy) and is followed by a consumption of coagulation factors combined with a platelet dysfunction (hypocoagulability). This chain of events leaves the patients in a paradoxical situation, where microvascular thrombus formation causes a perturbation in the microcirculation, leading to multiple organ failure, complicated by impairment of fibrinolysis. On the other hand patients experience a high risk for severe bleeding due to depletion of coagulation factors and platelets [24].

\section{Contact activation in severe infectious diseases}

With regard to the role of the contact system in severe infectious diseases it should be noted that it was already in 1970 reported that patients with hypotensive sepsis have significantly lower levels of contact factors in their blood than patients with sepsis alone [25]. Since then, several studies have been published showing that systemic contact activation has been found in patients with severe sepsis, septic shock and sepsis combined with SIRS and that this is often combined with a massive release of BK and a consumption of contact factors [26-28]. Notably, low levels of plasma kallikrein, FXII and HK during sepsis correlate with a fatal outcome of the disease [26, 29].

Until recently is was generally accepted that the contact system plays a secondary role in hemostasis, since patients with deficiencies in FXII, plasma kallikrein, or HK do not suffer from bleeding disorders. This point of view changed when the first data on FXI and FXII deficient mice were published and it was found that contact activation contributes to pathological thrombus formation in response to vessel injury 
$1 \quad[30,31]$. Whether the contact system contributes to pathologic coagulation disorders

2 in severe infectious diseases is controversial and discussed. For instance, Pixley and

3 colleagues reported that contact activation occurs in patients with DIC [32].

4 Pronounced activation of the system was also seen in children with meningococcal septic shock $[33,34]$ and in patients with streptococcal toxic shock syndrome (STSS) [35]. On the other hand it has been found that patients with STSS but without a bleeding tendency, had a prolonged aPTT [35], implying that contact activation has occurred. The latter findings are in line with an experimental baboon model of lethal E. coli bacteremia, showing that systemic contact activation is not combined with DIC, but with fatal hypotension, probably caused by the release of BK [36, 37]. It is noteworthy to mention that animals experienced an initial hypotension that was reversed, when treated with a human antibody against FXII and extended the life of the baboons [36]. However, more studies are required to unravel the role of the contact system in the induction of coagulation disorders in severe infectious diseases.

\section{Contact activation and inflammation}

The release of $\mathrm{BK}$ from $\mathrm{HK}$ is responsible for evoking inflammatory reactions [38]. There are two types of kinin receptors in humans, termed B1 and B2 receptors. Mice lacking both receptors have normal blood pressure and cardiac morphology and they are unable to respond to stimulation with kinins [39]. Importantly, lipopolysaccharide

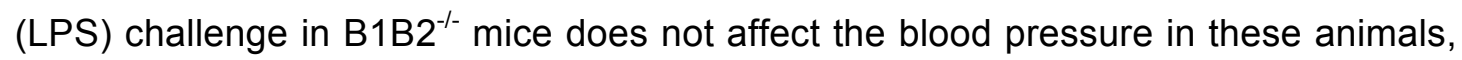
while blood pressure was markedly decreased in wild-type animals [39]. Other studies have shown a protective effect of kinin antagonists in a lethal LPS model in rats [40]. With regards to the molecular mechanisms leading to the induction of these inflammatory reactions, Fischer et al. conducted experiments showing that BKinduced vasoconstriction in a rat LPS model can be prevented by the application of cyclooxygenase inhibitors and is dependent on the inducible nitric oxide synthase $[41,42]$. These findings imply that the induction of second-generation mediators by kinins significantly contribute to the inflammatory reactions seen in the LPS challenged animals. Interestingly, many bacterial proteinases have evolved mechanisms to trigger the release of BK from HK, either by cleaving HK directly or by activating PK. One of the first reports was already published in 1984 by Matsumoto and colleagues who described a metallo protease from Serratia marcescens with plasma kallikrein-like properties [43]. Since then, bacterial proteinases from many other bacterial species have been described to activate the contact system in one way or another (for a review see [44]). It has been suggested that the vascular 
1 permeability induced by the released kinins promotes an influx of plasma into the site

2 of infection that serves as nutrients and facilitates spreading of the microorganisms

3 within the infected host [44].

\section{Contact activation caused by microorganisms}

As early as 1983 it was shown by Kalter et al. that LPS of Gram-negative bacteria as well as peptidoglycan and teichoic acid of Gram-positive bacteria have the ability to induce activation of the contact system [45]. While the LPS binding-site in HK was recently resolved [46], no information on the interaction sites between pepidoglycans and teichoic acid with contact factors has been published to date. Subsequent studies have shown that bacterial surface proteins, such as $M$ protein of Streptococcus pyogenes or thin aggregative fimbriae expressed by Escherichia coli and Salmonella, are able to bind and assemble contact factors on their surfaces and trigger the activation of the system [6, 47]. An activation of the contact system by Staphylococcus aureus and Rickettsia rickettsii has also been described $[7,48]$ although the bacterial proteins that promote the binding to the contact factors have not yet been identified. In addition, and as mentioned above, many bacterial proteinases have been described to cleave $\mathrm{HK}$ and release $\mathrm{BK}$, and recently it has been reported that fungal pathogens also (Candida species) interact with factors of the contact system [49].

\section{Contact System Inhibition - a potential therapeutic intervention?}

One can wonder whether the contact system is an interesting target for drug development, as it also has protective effects. For instance, it plays an important role in innate immunity via the generation of HK-derived antibacterial peptides and kinin induced recruitment of neutrophils [50-52]. However, these responses take place at an early stage and are most likely restricted to the site of infection, while under systemic conditions a massive activation of the contact system may lead to the release of pathologic levels of kinins and a consumption of contact factors (for a review see [26]). Notably, low levels of some contact factors are an indication of an unfavorable outcome of the disease [26]. The prevention of a systemic activation could therefore benefit seriously ill patients.

Kinins are potent inflammatory mediators, causing symptoms such as increased vascular permeability, vascular leakage, hypotension and edema formation, which are a hallmark of severe infectious diseases. Kinin receptors are therefore attractive targets for drug development. Two receptors (B1R and B2R) have been described in humans, of which both have completely different pharmacologic profiles (for a review 
1 see [53]). B2R is constitutively expressed by most cell types and rapidly internalized 2 upon BK binding [53], while B1R is generally expressed at a low level in normal

3 tissue, but up-regulated upon stimulation with proinflammatory agents such as LPS

4 or endotoxins from $S$. aureus and $S$. pyogenes [54-56]. A number of kinin receptor antagonists have been developed and successfully used in animal models [57]. However, so far only a B2R antagonist (Deltibant) has been used in clinical trials for sepsis [58]. The drug was used in patients with SIRS and presumed sepsis in a randomized, double-blind, placebo-controlled trial. Deltibant observed no significant effect on risk-adjusted 28-day survival, but posthoc analysis of risk-adjusted 7-day survival showed a non-significant trend toward improvement. Furthermore, the 2811 day risk-adjusted survival in the prospectively defined subset of patients with Gram12 negative infections showed a statistically significant improvement [58]. Considering 13 the important role of the B1R in infectious diseases [59], theoretically, a combination 14 of B1R and B2R antagonists could be an interesting alternative approach for a 15 clinical trial.

16 C1 inhibitor is a member of the family of serine proteinase inhibitors and a major 17 regulator of the complement and contact systems. It has been reported that levels of 18 proteolytically inactivated $\mathrm{C} 1$ inhibitor are increased in septic patients [60]. Notably, 19 treatment with $\mathrm{C} 1$ inhibitor during sepsis attenuated contact activation and had a 20 beneficial effect on hypotension and renal dysfunction [61-63]. The results from 21 clinical studies, therefore, indicate that therapeutic administration of C1 inhibitor may 22 be safe, even though major bleedings have been observed in patients as compared 23 to the control groups [62]. It should be noted that $\mathrm{C} 1$ inhibitor inhibits serine 24 proteases irreversibly and may also block other proteases from the coagulation 25 cascade, if applied in therapeutic doses.

26 A completely different mode of contact system inhibition was recently reported in a 27 mouse model of invasive streptococcal infections. In this study a synthetic peptide 28 derived from domain 5 of $\mathrm{HK}$, resembling the binding site to eukaryotic and bacterial 29 surfaces (see above), was shown to prevent activation of the contact system on 30 these surfaces [64]. Treatment with the peptide protected mice with invasive 31 Streptococcus pyogenes infection from lung damage and, in combination with 32 clindamycin, the peptide also significantly improved the overall survival. However, the 33 peptide has not been used in clinical trials yet.

\section{Concluding remarks}

36 Therapies in sepsis, severe sepsis, and septic shock, which are entirely based on 37 antibiotics, are combined with a high risk to fail, and thus, there is an urgent need for 
1 novel antimicrobial strategies. Concepts focusing on the prevention of patho-

2 physiological mechanisms in severe infectious diseases, such as the systemic 3 activation of important host effector systems, are therefore promising and may have 4 a considerable impact. For instance, treatment with activated protein C (APC) has 5 been found to reduce the mortality in severe sepsis patients [65]. However, APC 6 administration is combined with severe side effects (bleeding) and, thus, its 7 application is restricted to patients at high risk of death.

8 Patients with deficiencies in FXII, plasma kallikrein, or HK do not experience severe 9 bleeding disorders. The inhibition of the contact system at the initial stage of an 10 infection is therefore an interesting therapeutic approach to prevent hyper11 inflammatory reactions. This concept is in line with findings that the treatment of 12 sepsis patients with $\mathrm{C} 1$ inhibitor results in a beneficial clinical outcome. However, the 13 study also showed that patients still suffer from severe bleedings, probably because 14 C1 inhibitor also targets other coagulation factors apart from plasma kallikrein. It is 15 therefore tempting to speculate that more specific contact inhibitors with a saver 16 pharmacologic profile are promising candidates for the development of novel 17 antimicrobial therapies. 


\section{Acknowledgements}

2 This work was supported in part by the foundations of Alfred Österlund, Crafoord, 3 Greta and Johan Kock, the Blood and Defence Network and the Vascular Wall 4 Programme at Lund University, the Medical Faculty, Lund University, the Swedish 5 Research Council, and Hansa Medical. Hansa Medical, that in part funded this study 6 has filed patent applications on $\mathrm{HKH} 20$. SO and $\mathrm{HH}$ are listed as inventors and the 7 applications are pending.

\section{Keywords}

11 Sepsis, coagulation, contact system, Streptococcus pyogenes 
1. Martin GS, Mannino DM, Eaton S, Moss M (2003) The epidemiology of sepsis in the United States from 1979 through 2000. N Engl J Med 348: 1546-1554

2. Riedemann NC, Guo RF, Ward PA (2003) Novel strategies for the treatment of sepsis. Nat Med 9: 517-524. DOI 10.1038/nm0503-517 nm0503-517 [pii] 3. Pixley RA, Zellis S, Bankes P, DeLa Cadena RA, Page JD, Scott CF, Kappelmayer J, Wyshock EG, Kelly JJ, Colman RW (1995) Prognostic value of assessing contact system activation and factor $\mathrm{V}$ in systemic inflammatory response syndrome. Crit Care Med 23: 41-51

4. Hasan AA, Cines DB, Herwald H, Schmaier AH, Müller-Esterl W (1995) Mapping the cell binding site on high molecular weight kininogen domain 5. J BiolChem 270: 19256-19261

5. Herwald H, Mörgelin M, Svensson HG, Sjöbring U (2001) Zinc-dependent conformational changes in domain D5 of high molecular mass kininogen modulate contact activation. Eur J Biochem 268: 396-404

6. Ben Nasr AB, Herwald H, Müller-Esterl W, Björck L (1995) Human kininogens interact with $M$ protein, a bacterial surface protein and virulence determinant. Biochem J 305: 173-180

7. Mattsson E, Herwald H, Cramer H, Persson K, Sjöbring U, Björck L (2001) Staphylococcus aureus induces release of bradykinin in human plasma. Infect Immun 69: $3877-3882$

8. Herwald H, Dedio J, Kellner R, Loos M, Müller-Esterl W (1996) Isolation and characterization of the kininogen-binding protein $\mathrm{p} 33$ from endothelial cells. Identity with the gC1q receptor. J Biol Chem 271: 13040-13047

9. Mahdi F, Shariat-Madar Z, Kuo A, Carinato M, Cines DB, Schmaier AH (2004) Mapping the interaction between high molecular mass kininogen and the urokinase plasminogen activator receptor. J Biol Chem 279: 16621-16628. DOI 10.1074/jbc.M313850200

M313850200 [pii]

10. Nakazawa Y, Joseph K, Kaplan AP (2002) Inhibition of contact activation by a kininogen peptide (HKH20) derived from domain 5. International immunopharmacology 2: 1875-1885. DOI S1567-5769(02)00182-0 [pii]

11. Perkins R, Ngo MD, Mahdi F, Shariat-Madar Z (2008) Identification of lipopolysaccharide binding site on high molecular weight kininogen. Biochem Biophys Res Commun 366: 938-943. DOI S0006-291X(07)02654-X [pii] $\underline{10.1016 / \mathrm{j} . \mathrm{bbrc} .2007 .12 .042}$

12. Nordahl EA, Rydengård V, Mörgelin M, Schmidtchen A (2005) Domain 5 of high molecular weight kininogen is antibacterial. J Biol Chem 280: 34832-34839

13. Colman RW, Jameson BA, Lin Y, Johnson D, Mousa SA (2000) Domain 5 of high molecular weight kininogen (kininostatin) down-regulates endothelial cell proliferation and migration and inhibits angiogenesis. Blood 95: 543-550

14. Colman RW, Schmaier AH (1997) Contact system: a vascular biology modulator with anticoagulant, profibrinolytic, antiadhesive, and proinflammatory attributes. Blood 90: 3819-3843

47 15. Kunapuli SP, DeLa Cadena RA, Colman RW (1993) Deletion mutagenesis of 48 high molecular weight kininogen light chain. Identification of two anionic surface binding subdomains. J Biol Chem 268: 2486-2492 
1 16. Kannemeier C, Shibamiya A, Nakazawa F, Trusheim H, Ruppert C, Markart 2 P, Song Y, Tzima E, Kennerknecht E, Niepmann M, von Bruehl ML, Sedding D, 3 Massberg S, Günther A, Engelmann B, Preissner KT (2007) Extracellular RNA 4 constitutes a natural procoagulant cofactor in blood coagulation. Proceedings of the 5 National Academy of Sciences of the United States of America 104: 6388-6393. DOI $6 \quad 0608647104$ [pii]

$7 \quad 10.1073 /$ pnas.0608647104

8 17. Oehmcke S, Mörgelin M, Herwald H (2009) Activation of the human contact 9 system on neutrophil extracellular traps. J Innate Immun 1: 225-231

10 18. Davis AE, 3rd (2008) Hereditary angioedema: a current state-of-the-art 11 review, III: mechanisms of hereditary angioedema. Ann Allergy Asthma Immunol 12 100: $\mathrm{S} 7-12$

13 19. Frick IM, Björck L, Herwald H (2007) The dual role of the contact system in 14 bacterial infectious disease. Thromb Haemost 98: 497-502

15 20. Russell JA (2006) Management of sepsis. N Engl J Med 355: 1699-1713

16 21. Rittirsch D, Flierl MA, Ward PA (2008) Harmful molecular mechanisms in 10.1038/nri2402

22. Fourrier F, Jourdain M, Tournois A, Caron C, Goudemand J, Chopin C (1995) Coagulation inhibitor substitution during sepsis. Intensive Care Med 21 Suppl 2: S264-268

23. Risberg B, Andreasson S, Eriksson E (1991) Disseminated intravascular coagulation. Acta Anaesthesiol Scand Suppl 95: 60-71

24. Levi M, Ten Cate H (1999) Disseminated intravascular coagulation. N Engl J Med 341: 586-592

25. Mason JW, Kleeberg U, Dolan P, Colman RW (1970) Plasma kallikrein and Hageman factor in Gram-negative bacteremia. Ann Intern Med 73: 545-551

26. Pixley RA, Colman RW (1997) The kallikrein-kinin system in sepsis syndrome. Handbook of Immunopharmacology - The Kinin System Farmer SG, ed New York: Academic Press: 173-186

27. Saugstad OD, Buo L, Johansen HT, Roise O, Aasen AO (1992) Activation of the plasma kallikrein-kinin system in respiratory distress syndrome. Pediatr Res 32: 431-435

28. Mattsson E, Herwald H, Cramer H, Persson K, Sjöbring U, Björck L (2001) Staphylococcus aureus induces release of bradykinin in human plasma. Infect Immun 69: 3877-3882. DOI 10.1128/IAI.69.6.3877-3882.2001

29. Aasen AO, Smith-Erichsen N, Amundsen E (1983) Plasma kallikrein-kinin system in septicemia. Arch Surg 118: 343-346

30. Renne T, Pozgajova M, Gruner S, Schuh K, Pauer HU, Burfeind P, Gailani D, Nieswandt B (2005) Defective thrombus formation in mice lacking coagulation factor XII. J Exp Med 202: 271-281. DOI jem.20050664 [pii] 10.1084/jem.20050664

31. Gailani D, Renne $\mathrm{T}$ (2007) Intrinsic pathway of coagulation and arterial thrombosis. Arterioscler Thromb Vasc Biol 27: 2507-2513. DOI ATVBAHA.107.155952 [pii]

10.1161/ATVBAHA.107.155952

32. Kaufman N, Page JD, Pixley RA, Schein R, Schmaier AH, Colman RW (1991) Alpha 2-macroglobulin-kallikrein complexes detect contact system activation in hereditary angioedema and human sepsis. Blood 77: 2660-2667 
33. van Deuren M, Brandtzaeg P, van der Meer JW (2000) Update on meningococcal disease with emphasis on pathogenesis and clinical management. Clin Microbiol Rev 13: 144-166

4 34. Wuillemin WA, Fijnvandraat K, Derkx BH, Peters M, Vreede W, ten Cate H, 5 Hack CE (1995) Activation of the intrinsic pathway of coagulation in children with

35. Sriskandan S, Cohen J (2000) Kallikrein-kinin system activation in streptococcal toxic shock syndrome. Clin Infect Dis 30: 961-962

36. Pixley RA, De La Cadena R, Page JD, Kaufman N, Wyshock EG, Chang A, Taylor FBJ, Colman RW (1993) The contact system contributes to hypotension but not disseminated intravascular coagulation in lethal bacteremia. In vivo use of a monoclonal anti-factor XII antibody to block contact activation in baboons. J Clin Invest 91: 61-68

37. Pixley RA, DeLa Cadena RA, Page JD, Kaufman N, Wyshock EG, Colman RW, Chang A, Taylor FB, Jr. (1992) Activation of the contact system in lethal hypotensive bacteremia in a baboon model. Am J Pathol 140: 897-906

38. Campbell DJ (2001) The kallikrein-kinin system in humans. Clin Exp Pharmacol Physiol 28: 1060-1065

39. Cayla C, Todiras M, Iliescu R, Saul VV, Gross V, Pilz B, Chai G, Merino VF, Pesquero JB, Baltatu OC, Bader M (2007) Mice deficient for both kinin receptors are normotensive and protected from endotoxin-induced hypotension. FASEB J 21: 16891698. DOI fj.06-7175com [pii] 10.1096/fj.06-7175com

40. Morinelli TA, Webb JG, Jaffa AA, Privitera PJ, Margolius HS (2001) A metabolic fragment of bradykinin, Arg-Pro-Pro-Gly-Phe, protects against the deleterious effects of lipopolysaccharide in rats. J Pharmacol Exp Ther 296: 71-76

41. Fischer LG, Hollmann MW, Horstman DJ, Rich GF (2000) Cyclooxygenase inhibitors attenuate bradykinin-induced vasoconstriction in septic isolated rat lungs. Anesth Analg 90: 625-631

42. Fischer LG, Hilpert JH, Freise H, Wendholt D, Van Aken H, Sielenkamper AW (2004) Bradykinin-induced pulmonary vasoconstriction is time and inducible nitric oxide synthase dependent in a peritonitis sepsis model. Anesth Analg 99: 864871. DOI 10.1213/01.ANE.0000133000.65613.F5 99/3/864 [pii]

43. Matsumoto K, Yamamoto T, Kamata R, Maeda H (1984) Pathogenesis of serratial infection: activation of the Hageman factor-prekallikrein cascade by serratial protease. J Biochem 96: 739-749

44. Potempa J, Pike RN (2009) Corruption of Innate Immunity by Bacterial Proteases. J Innate Immun 1: 70-87

45. Kalter ES, van Dijk WC, Timmerman A, Verhoef J, Bouma BN (1983) Activation of purified human plasma prekallikrein triggered by cell wall fractions of Escherichia coli and Staphylococcus aureus. J Infect Dis 148: 682-691

46. Perkins R, Ngo MD, Mahdi F, Shariat-Madar Z (2008) Identification of lipopolysaccharide binding site on high molecular weight kininogen. Biochem Biophys Res Commun 366: 938-943. DOI S0006-291X(07)02654-X [pii] 10.1016/j.bbrc.2007.12.042

47. Herwald H, Mörgelin M, Olsén A, Rhen M, Dahlbäck B, Müller-Esterl W, Björck L (1998) Activation of the contact-phase system on bacterial surfaces--a clue to serious complications in infectious diseases. Nat Med 4: 298-302 
1 48. Yamada T, Harber P, Pettit GW, Wing DA, Oster CN (1978) Activation of the

2 kallikrein-kinin system in Rocky Mountain spotted fever. Ann Intern Med 88: 764-

3768

4 49. Rapala-Kozik M, Karkowska J, Jacher A, Golda A, Barbasz A, Guevara-Lora

5 I, Kozik A (2008) Kininogen adsorption to the cell surface of Candida spp.

6 International immunopharmacology 8: 237-241

7 50. Andersson Nordahl E, Rydengård V, Mörgelin M, Schmidtchen A (2005)

8 Domain 5 of high molecular weight kininogen is antibacterial. J Biol Chem in press

9 51. Araujo RC, Kettritz R, Fichtner I, Paiva AC, Pesquero JB, Bader M (2001)

10 Altered neutrophil homeostasis in kinin B1 receptor-deficient mice. Biol Chem 382:

11 91-95. DOI 10.1515/BC.2001.014

12 52. Frick IM, Akesson P, Herwald H, Mörgelin M, Malmsten M, Nagler DK,

13 Björck L (2006) The contact system-a novel branch of innate immunity generating 14 antibacterial peptides. EMBO J 25: 5569-5578

15 53. Leeb-Lundberg LM, Marceau F, Müller-Esterl W, Pettibone DJ, Zuraw BL 16 (2005) International union of pharmacology. XLV. Classification of the kinin receptor 17 family: from molecular mechanisms to pathophysiological consequences. Pharmacol 18 Rev 57: 27-77. DOI 57/1/27 [pii]

$19 \quad 10.1124 /$ pr.57.1.2

20 54. Schremmer-Danninger E, Offner A, Siebeck M, Roscher AA (1998) B1

21 bradykinin receptors and carboxypeptidase $\mathrm{M}$ are both upregulated in the aorta of pigs 22 after LPS infusion. Biochemical and biophysical research communications 243: 24623 252. DOI S0006-291X(97)97999-7 [pii]

24 10.1006/bbrc.1997.7999

25 55. Bengtson SH, Phagoo SB, Norrby-Teglund A, Påhlman L, Mörgelin M, 26 Zuraw BL, Leeb-Lundberg LMF, Herwald H (2006) Kinin receptor expression during Staphylococcus aureus infection. Blood 108: 2055-2063

56. Bengtson SH, Sandén C, Mörgelin M, Marx PF, Leeb-Lundberg FLM, Meijers JCM, Herwald H (2009) Activation of TAFI on the surface of Streptococcus pyogenes evokes inflammatory reactions by modulating the kallikrein/kinin system. $\mathbf{J}$ Innate Immun 1: 18-28

57. Marceau F, Regoli D (2004) Bradykinin receptor ligands: therapeutic perspectives. Nat Rev Drug Discov 3: 845-852

58. Fein AM, Bernard GR, Criner GJ, Fletcher EC, Good JT, Jr., Knaus WA, Levy H, Matuschak GM, Shanies HM, Taylor RW, Rodell TC (1997) Treatment of severe systemic inflammatory response syndrome and sepsis with a novel bradykinin antagonist, deltibant (CP-0127). Results of a randomized, double-blind, placebocontrolled trial. CP-0127 SIRS and Sepsis Study Group. Jama 277: 482-487

59. Merino VF, Todiras M, Campos LA, Saul V, Popova E, Baltatu OC, Pesquero JB, Bader M (2008) Increased susceptibility to endotoxic shock in transgenic rats with endothelial overexpression of kinin B(1) receptors. J Mol Med 86: 791-798. DOI 10.1007/s00109-008-0345-z

60. Nuijens JH, Eerenberg-Belmer AJ, Huijbregts CC, Schreuder WO, FeltBersma RJ, Abbink JJ, Thijs LG, Hack CE (1989) Proteolytic inactivation of plasma C1 - inhibitor in sepsis. The Journal of clinical investigation 84: 443-450

61. Caliezi C, Wuillemin WA, Zeerleder S, Redondo M, Eisele B, Hack CE (2000) C1-Esterase Inhibitor: An Anti-Inflammatory Agent and Its Potential Use in the Treatment of Diseases Other Than Hereditary Angioedema. Pharmacol Rev 52: 91-112 
62. Caliezi C, Zeerleder S, Redondo M, Regli B, Rothen HU, Zurcher-Zenklusen R, Rieben R, Devay J, Hack CE, Lammle B, Wuillemin WA (2002) C1-inhibitor in patients with severe sepsis and septic shock: beneficial effect on renal dysfunction. Critical care medicine 30: 1722-1728

5 63. Hack CE, Ogilvie AC, Eisele B, Eerenberg AJ, Wagstaff J, Thijs LG (1993)

6 C1-inhibitor substitution therapy in septic shock and in the vascular leak syndrome 7 induced by high doses of interleukin-2. Intensive Care Med 19: S19-28

8 64. Oehmcke S, Shannon O, von Köckritz-Blickwede M, Mörgelin M, Linder A,

9 Olin AI, Björck L, Herwald H (2009) Treatment of invasive streptococcal infection

10 with a peptide derived from human high-molecular weight kininogen. Blood 114:

11 444-451. DOI blood-2008-10-182527 [pii]

12 10.1182/blood-2008-10-182527

13 65. Bernard GR, Vincent JL, Laterre PF, LaRosa SP, Dhainaut JF, Lopez14 Rodriguez A, Steingrub JS, Garber GE, Helterbrand JD, Ely EW, Fisher CJ, Jr. (2001) 15 Efficacy and safety of recombinant human activated protein $\mathrm{C}$ for severe sepsis. $\mathrm{N}$ 16 Engl J Med 344: 699-709 


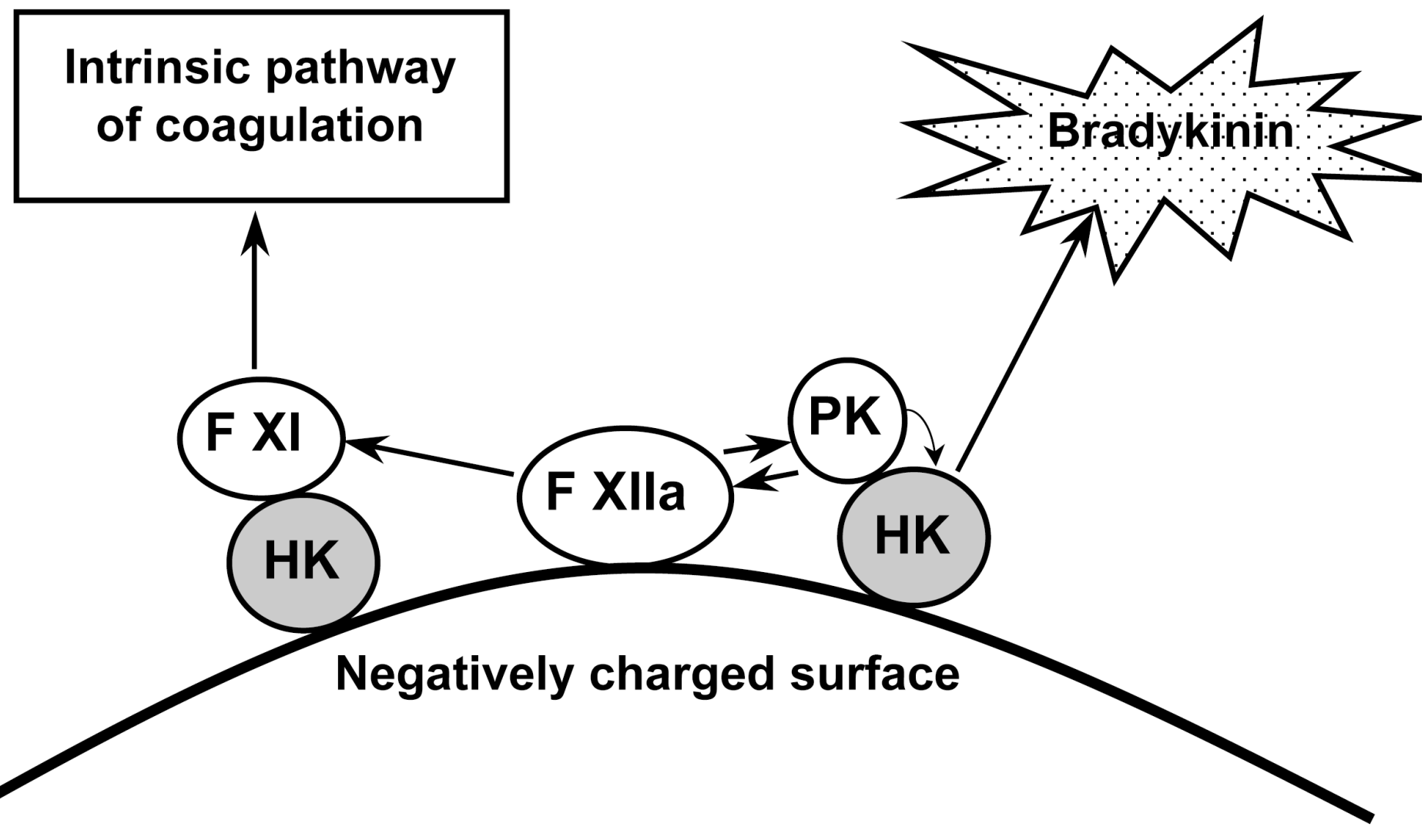


1 Figure Legend:

2

3 Fig. 1: The contact system. Assembly of contact system factors on a negatively 4 charged surface activates FXII. FXII activates FXI that triggers the intrinsic pathway of coagulation and plasma kallikrein. Plasma kallikrein cleaves HK, followed by the release of the proinflammatory peptide BK. 